\title{
Gold Alloy Spinnerets for the Production of Viscose Rayon
}

\author{
Werner Funk and Gerhard Reinacher
}

Degussa, Hanau, West Germany

For decades the most important application for gold alloys in chemical engineering has been as platinum-gold alloys in the form of spinnerets for the manufacture of viscose rayon since these must stand up to highly aggressive conditions. As with many others, this branch of industry has grown out of the rapid development of organic chemistry. For thousands of years man has known how to convert natural cellulose fibres such as flax and cotton into yarn and cloth, and towards the end of the last century various methods were discovered for converting native cellulose into viscous ropy solutions and, by emulating the spider or the silkworm, spinning these into threads.

\section{The Process and its History}

One of these methods consists in steeping wood cellulose, usually in the form of pulp in a 17 to 20 per cent caustic soda solution. The product is crushed and placed in rotary drums together with a 28 to 30 per cent carbon bisulphide solution, where at a temperature of 20 to $30^{\circ} \mathrm{C}$ maintained for between one and three hours it is converted into cellulose sodium xanthate.

This is an orange coloured tacky mass. When mixed with a 4 to 10 per cent caustic soda solution a viscous solution is obtained. This was called "Viscose" by its inventor C. F. Cross who, in collaboration with E. J. Bevan and C. Beadle (1), patented the process in 1891. In $1898 \mathrm{C}$. H. Stearn (2) had the idea of spinning viscose into threads for use as carbon elements in electric light bulbs. His ammonium chloride bath for coagulating the viscose threads was replaced in 1905 by $M$. Müller and P. Koppe (3) with a bath consisting of diluted sulphuric acid and sodium sulphate which formula, with slight variations, is still being used today.

Depending on the type of rayon required, the spinning baths contain 50 to $160 \mathrm{~g} / 1$ sulphuric acid, 120 to $340 \mathrm{~g} / 1$ sodium sulphate and 5 to $90 \mathrm{~g} / \mathrm{l}$ zinc sulphate. After maturing at a temperature of 12 to $15^{\circ} \mathrm{C}$, the evacuated and filtered alkaline viscose is forced into this bath at a pressure of 3 to 5 atmospheres through bushings or spinnerets whose faces are pierced by holes ranging from 40 to 120 microns in diameter.

In the coagulation bath both alkali and carbon bi- sulphide are removed from the fine viscose jets and these coagulate into gel threads of regenerated cellulose. To increase their strength the threads are then pulled away from the spinnerets and straightened, and subsequently twisted into yarn and spooled.

Viscose rayon manufacture was started in 1905 by Samuel Courtauld in Coventry in England and on the Continent by Continentale Viscose G.m.b.H. in Breslau. By 1920, annual world production had reached 15,000 tons, in 1940 it was more than half a million tons, by 1960 it had reached 2.4 million tons and by 1971, 3 million tons. The last two figures include cuprammonium fibres.

Even in the early days of viscose rayon manufacture the idea occurred to cut the fibre cable into staple fibre in order to produce a wool or cotton-like thread. Attempts to produce staple fibre on an industrial scale were first made in Germany in 1916, and by 1940 their production had outstripped that of yarn made from continuous threads.

\section{The Spinneret}

The spinneret is the important and decisive factor in the spinning process, as it constitutes the formative element between the spinning solution and the spun thread. It is shaped like an inverted top-hat with a narrow clamping flange, its chief feature being a series of holes drilled in its face. The cross-section of these holes governs the shape, and the excellence

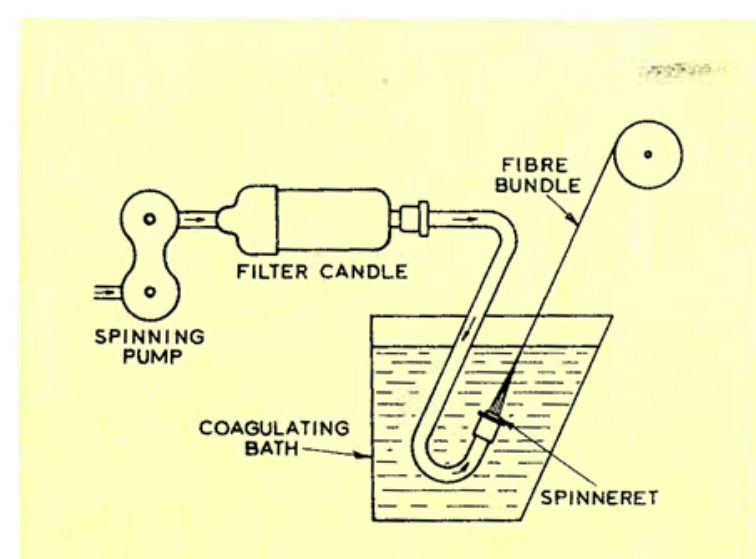

A diagrammatic representation of the viscose rayon spinning process 


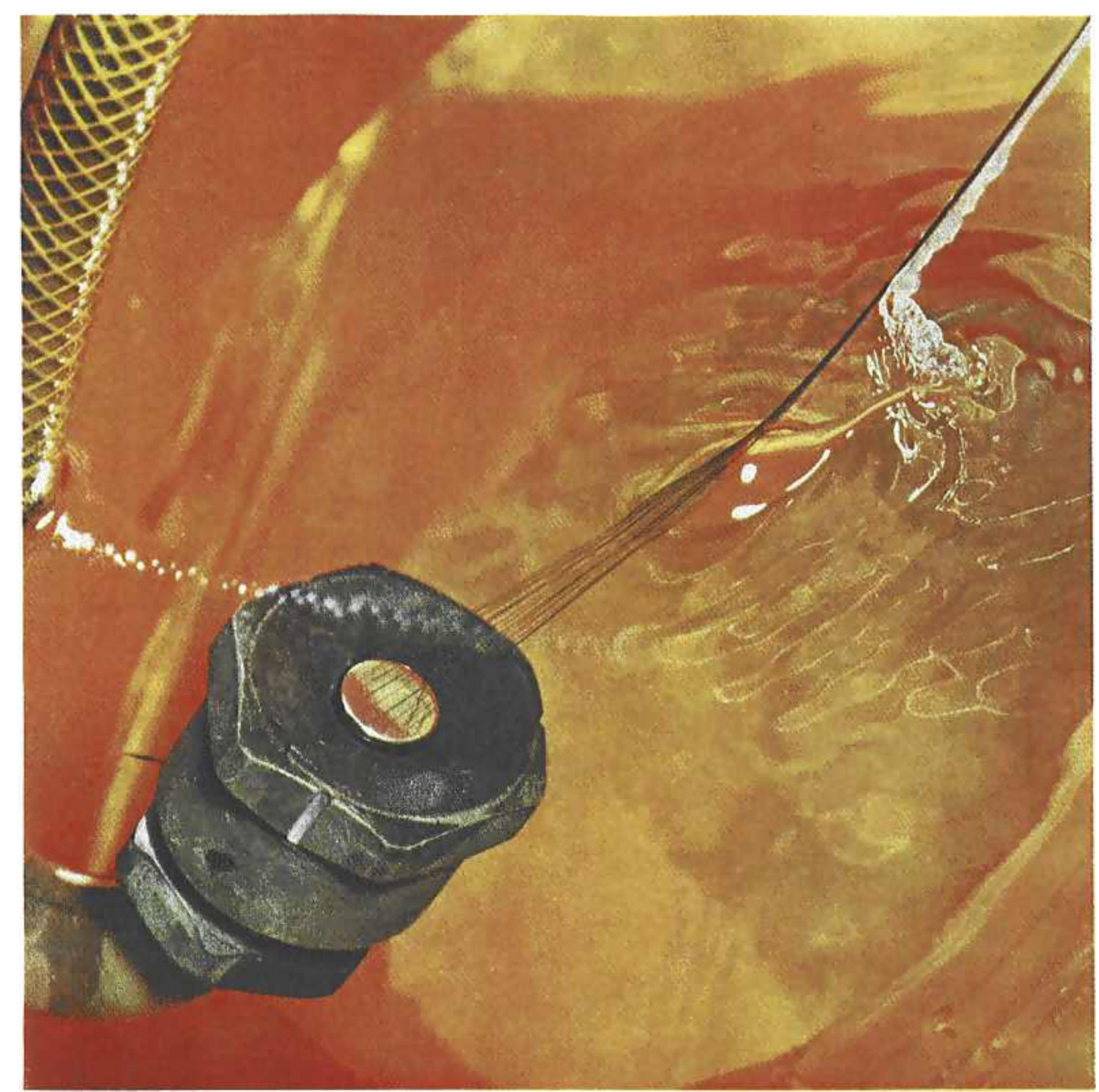

The birth of a fibre. The instant of formation of a viscose rayon fibre is clearly shown in this photograph. The alkaline solution of cellulose xanthate, forced through the many tiny holes in the platinumgold alloy spinneret, meets the acidic solution in the coagulating bath and is immediately regenerated as cellulose. Only gold alloys, specially heat-treated to high values of hardness, can withstand the severely corrosive conditions on either side of the spinneret face and also resist attrition of the holes which govern the size and quality of the fibres.

Photograph by Glanzstoff A.G.

of their finish governs the quality of the thread. From a mechanical point of view, the greatest importance attaches to the accuracy of the drilled holes, to the sharpness of edges on the outlet side, and to the smoothness of the bore walls and of the outer face of the spinneret.

Moreover, the spinneret material must be resistant to the corrosive influence of the alkaline viscose solution on the inlet side and to the acid spinning bath on the outlet side of the spinneret, as well as to the cleaning acids used, such as chromosulphuric acid or concentrated sulphuric acid at temperatures of 90 to $100^{\circ} \mathrm{C}$. These properties are indispensable for good quality fibres. For economic reasons too it is most important that the spinnerets should continue to operate for as long as possible before the holes become clogged by deposits from the viscose solution or even from the coagulating bath, necessitating removal and cleaning.

In addition the spinnerets must have long life. This is dependent chiefly on their resistance to attrition, that is their corrosion resistance and the hardness of the metal. A high degree of hardness prevents enlargement of the holes, rounding of the outlet edges as well as buckling of the spinneret face under spinning pressure and makes for high resistance against scratching which may occur during cleaning, replacement and at the start of the spinning cycle.

Good corrosion resistance apart, the development of spinneret materials was mainly directed towards achieving the highest feasible hardness while re- 


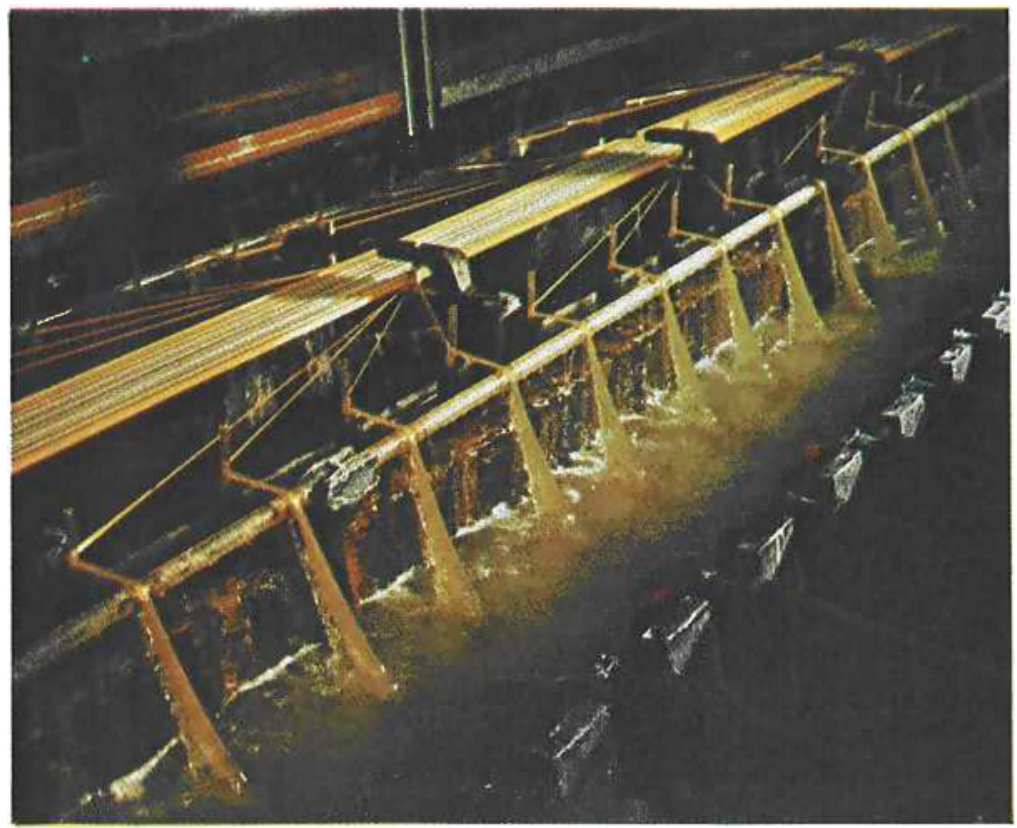

Many thousands of platinum-gold alloy spinnerets are in use in any one viscose rayon plant. This is one wet spinning unit in the works of Glanzstoff A.G. at Wuppertal

taining the advantages of good working and drilling properties which are ultimately decisive for the quality of the holes.

\section{The Development of Spinneret Materials}

The fragility and insufficient precision of the glass spinnerets used in the early days prompted Friedrich Eilfeld (4) in 1908 to produce the first metal spinneret for viscose rayon manufacture in pure platinum. This is, of course, resistant to both the alkaline viscose solution and to the acid spinning bath, but since the hardness of the pure metal, around 40 Brinell, was inadequate in the long run, efforts were made to raise it to about 65 by alloying with up to 5 per cent iridium $(5,6)$ or 2 per cent ruthenium (7). Apart from these platinum-rich alloys, a cheaper 10 per cent platinum-gold alloy was introduced in 1925 (8). Its corrosion resistance was adequate, but not so its mechanical strength, since its hardness was again only about 40 . This alloy was the forerunner of a 10 per cent palladiumgold alloy (7), chosen because palladium is not only cheaper than platinum but also has a lower specific gravity, but its hardness again showed the same low level.

It was, therefore, a big step forward when successful efforts were made in 1930 to precipitationharden both these alloys by heat treatment up to

To increase their strength, the newly formed fibres are pulled away from the spinning bath, and then twisted into yarn and spooled

Photograph by Glanzstoff A.G.
Brinell values of 130 by adding small quantities of base metals. Iron, cobalt, nicke] $(9,10,11)$, zinc (12), tin (13) or magnesium $(14,10)$ are examples of the additives used, but these alloys were soon found to be inadequate for spinneret purposes because, during the simultaneous hardening of a large quantity, the formation of relatively base phases due

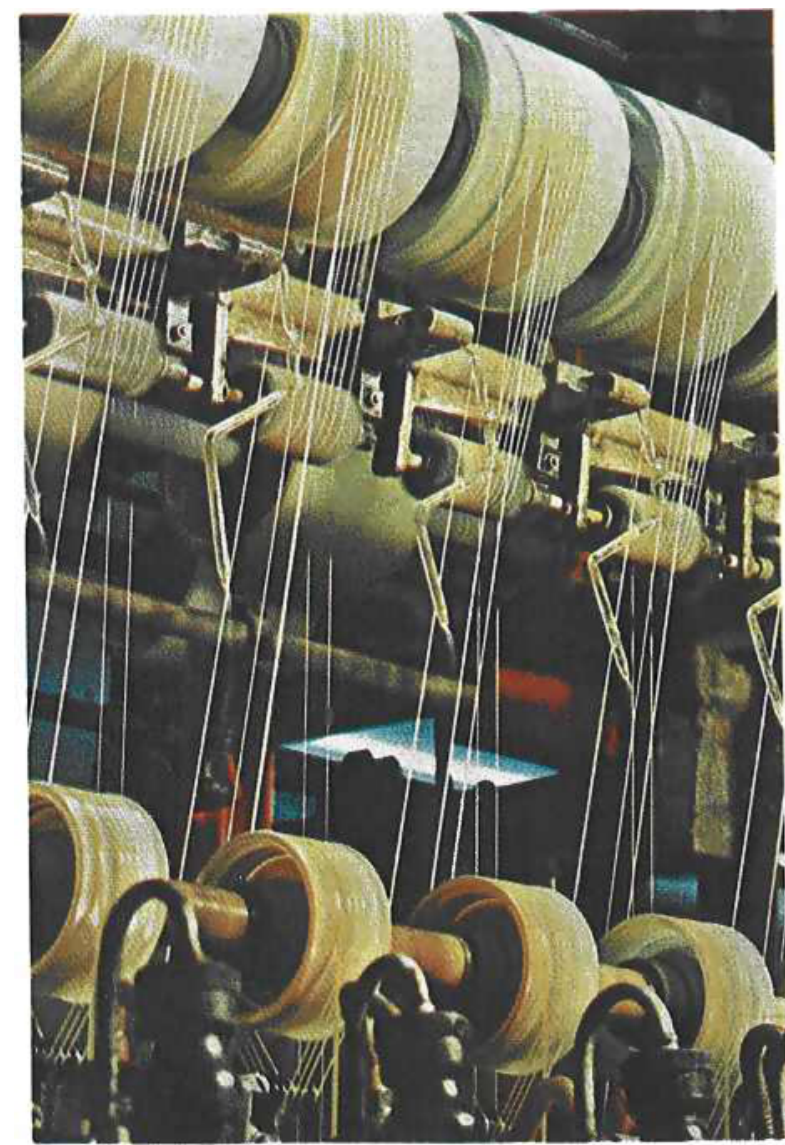


to partial overhardening could not be entirely avoided in a number of cases, with the result that the spinneret showed traces of corrosion in service.

All these spinneret materials were abandoned when it was found that the corrosion resistant binary platinum-gold alloys could be precipitation-hardened without the need for base metal additions, provided that their platinum content was raised to 20 per cent and over. According to studies carried out by A. T. Grigorijew (15) as well as by C. H. Johansson and J. O. Linde (16) between 1928 and 1930, a miscibility gap in the solid state is present in the platinum-gold system with a critical limit at 60 per cent platinum and a temperature of $1260^{\circ} \mathrm{C}$ which spreads with progressive cooling to the point where at $600^{\circ} \mathrm{C}$ it extends from 20 up to 95 per cent platinum content.

A later study of the platinumgold system was carried out by Darling, Mintern and Chaston (17) in 1952, and their constitutional diagram is reproduced here.

The miscibility gap enabled hardening of the relevant alloys by high temperature precipitationhardening. As long ago as 1929, L. Nowack (12) announced that 20 and 25 per cent platinum-gold alloys could be precipitationhardened. After 1933 a 30 per cent platinum-gold alloy was introduced in Europe from America. This is capable of being hardened up to 200 Brinell, and allowed the production of thinner-walled spinnerets down to $0.2 \mathrm{~mm}$ in thickness, resulting in a notable saving of precious metal $(6,7)$. The greater hardness also enabled improved polishing of the bore walls and the outer spinneret face, with accompanying improvements in the quality of the rayon. The tendency of the alloy towards segregation, which increases with rising platinum contents, produced certain variations in hardness during precipitation-hardening unless the alloy was homogenised at high temperatures for long periods to the point where a coarse-grained structure developed. Also, the alloy became brittle after maximum hardening, but after 1935 these problems were largely eliminated by the addition of between 0.1 and 0.6 per cent rhodium (18).

The desire of viscose manufacturers for an even

harder spinneret alloy-to spin viscose threads to which titanium dioxide is added to give a matt finish and which acts as a scouring agent on the spinneret holes-was satisfied in 1936 when a method was found to work a 50/50 platinum-gold alloy (7) capable of being precipitation-hardened up to approximately 350 Brinell, again containing up to about 1 per cent rhodium (19). A similar effect was created by additions of 0.1 per cent rhenium and these additions were used, for example, for the $40 / 60$ platinum-gold alloy which can be hardened up to about $300(20)$, or alternatively using small additions of iridium (21).

Twenty years later $H$. Schmid (22) was able to explain the influence of rhodium in the precipitationhardening of these platinum-gold alloys. On account of their wide solidification range and the flatness of the middle part of the solidus line in the equilibrium diagram the alloys showed considerable segregation 
after casting. To compensate for this, the intensively rolled cast ingots were annealed for many hours at $1000^{\circ} \mathrm{C}$ and over. For complete elimination of segregation they would have to be annealed between $1100^{\circ}$ and $1250^{\circ} \mathrm{C}$ over very long periods; on the other hand, this would promote grain growth to the point where it would be difficult to obtain a satisfactory polish on the outer face of the spinneret or adequate smoothness of the bore walls. Schmid was able to prove that homogenisation of the heterogeneous structure by diffusion annealing should be carried out only until variations in the concentration of the gold-rich phase $\alpha_{1}$, are largely evened out, without affecting the platinum-rich phase $\alpha_{2}$. During final rolling of the sheet the latter constituent is extended into stringers. During solution annealing for the hardening process the grain size of the goldrich phase formed by recrystallisation is governed by the distance between the platinum stringers. One of the effects of rhodium is that rhodiumcontaining platinum-gold alloys retain their fine grained structure for much longer, even during extended annealing periods, because small additions of rhodium encourage segregation which directly affects the extent of the platinum-rich phase on solidification. On the other hand, additions of rhodium broaden the miscibility gap in the solid state towards gold. And, finally, they reduce the degree of saturation of the gold-rich phase in the quenched condition. This means a slight reduction in maximum hardness when precipitation-hardening alloys containing between 70 and 50 per cent gold, which is offset by a higher elongation.

On partially homogenised platinum-gold alloys with or without additions of rhodium Schmid (22) obtained maximum hardness values as given in the table as a function of the precipitation-hardening temperature.

After 80 per cent cold working of the cast ingots, the test pieces had undergone the following production stages: diffusion annealing for 14 hours at $1000^{\circ} \mathrm{C}$ followed by quenching in water; 96 per cent cold working to final thickness; solution annealing for 30 minutes at $1100^{\circ} \mathrm{C}$ (for $\mathrm{Pt}-\mathrm{Au} 25 / 75$ and $30 / 70$ ) or at $1150^{\circ} \mathrm{C}$ (for $0.5 / 25 / 74.5 \mathrm{Rh} / \mathrm{Pt} / \mathrm{Au}$ ) or $1200^{\circ} \mathrm{C}$ (for $50 / 50 \mathrm{Pt} / \mathrm{Au}$ and $1 / 49 / 50 \mathrm{Rh} / \mathrm{Pt} / \mathrm{Au}$ ) followed by quenching in water; precipitationhardening at the temperatures indicated in the table. Since hardening periods must be relatively short for spinneret manufacture, maximum hardnesses are not normally achieved in practice.

\section{Spinneret Manufacture}

Spinneret blanks are cupped from strip of 0.20 to $0.50 \mathrm{~mm}$ in thickness in the chosen gold alloy which, in view of the required precision and polish of the bore walls, must be of uniform structure and show a relatively small grain size. In the case of the 30 per cent platinum-gold alloy the spinnerets are produced by the following method: the blanks are cupped from strip having a hardness of 180 , followed by drilling, homogenisation and precipitation-hardening. By careful control of the processes of rolling, diffusion annealing, final rolling and solution annealing, an alloy containing 0.5 per cent rhodium will yield a fine-grained strip of 120 Vickers hardness. By hardening the drilled spinnerets the hardness is raised to approximately 220.

\section{Shape and Diameter of Holes}

Hole diameters vary between 60 and 120 micron for artificial silk, 38 and 60 micron for tyre cord, 55

\section{Maximum Vickers Hardness Values for Partially Factory Homogenised and Precipitation-Hardened}

Platinum-Gold Alloys as a Function of Temperature

\begin{tabular}{|c|c|c|c|c|c|c|c|c|c|c|c|c|}
\hline \multicolumn{3}{|c|}{$\begin{array}{l}\text { Concentration } \\
\text { in Weight per cent }\end{array}$} & \multicolumn{2}{|c|}{$650^{\circ} \mathrm{C}$} & \multicolumn{2}{|c|}{$600^{\circ} \mathrm{C}$} & \multicolumn{2}{|c|}{$550^{\circ} \mathrm{C}$} & \multicolumn{2}{|c|}{$500^{\circ} \mathrm{C}$} & \multicolumn{2}{|c|}{$450^{\circ} \mathrm{C}$} \\
\hline $\mathrm{Au}$ & $\mathrm{Pt}$ & $\mathrm{Rh}$ & Hours & Hardness & Hours & Hardness & Hours & Hardness & Hours & Hardness & Hours & Hardness \\
\hline 75 & 25 & - & 1 & 140 & 2 & 160 & 8 & 190 & 50 & 220 & $>300$ & $>200$ \\
\hline 74.5 & 25 & 0.5 & 0.7 & 170 & 1.6 & 195 & 6 & 220 & 50 & 220 & $>300$ & $>200$ \\
\hline 70 & 30 & - & 0.5 & 210 & 2 & 255 & 6 & 270 & 60 & 295 & $>300$ & $\approx 300$ \\
\hline 69.5 & 30 & 0.5 & 0.4 & 240 & 1.5 & 250 & 6 & 255 & 50 & 250 & $>300$ & $\approx 250$ \\
\hline 50 & 50 & - & 0.2 & 370 & 0.5 & 370 & 2 & 370 & 11 & 375 & 100 & 385 \\
\hline 50 & 49 & 1 & 0.2 & 295 & 0.5 & 315 & 2 & 315 & 11 & 325 & 110 & 330 \\
\hline
\end{tabular}




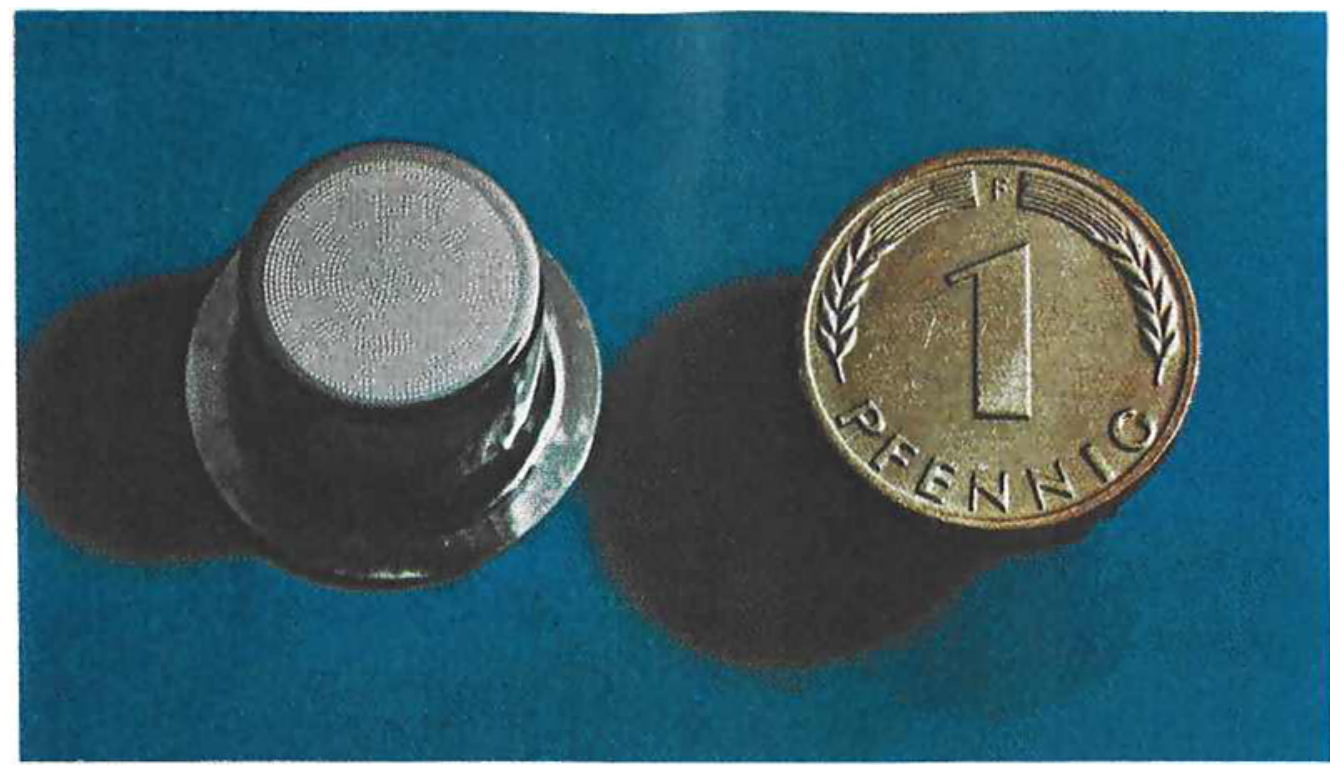

Spinnerets vary in diameter from about $12 \mathrm{~mm}$ to over $100 \mathrm{~mm}$. This very small spinneret, with 1,500 holes each 38 microns in diameter, is shown compared in size with a Pfennig. Larger sizes may have as many as 15,000 holes

and 90 micron for staple fibre, and 120 to 680 micron for carpeting. Normally, the thickness of the thread is governed by the hole diameter. On the other hand, the exact hole diameter required depends to a large extent on the ratio of injection rate to drawing-off rate of the viscose and there are no standard diameters for given Denier numbers.

The following values may serve as guidelines:

$\begin{array}{cc}\text { Individual } & \begin{array}{c}\text { Hole diameter } \\ \text { in micron }\end{array} \\ \text { Denier No. } & 40-60 \\ 1.00-1.50 & 60-80 \\ 1.50-2.50 & 80-90 \\ 2.50-3.75 & 90-150 \\ 3.75-15.00 & \end{array}$

The standard for individual threads is the denier. A thread may be said to be 1 denier if $9000 \mathrm{~m}$ of thread weigh $1 \mathrm{~g}$. The individual Denier No. multiplied by the number of holes is the total Denier No.

The holes are normally made up of a cylindrical section about 1 to 1.5 times the hole diameter in length, with a cone-shaped or hyperbolic inlet section as shown in the diagram. Particular care must be paid to achieving a smooth transition. An aperture angle of $22^{\circ}$ for the conical section has been found to be the best solution (23).

\section{Bore Finish and Tolerances}

The spinning performance of a spinneret is governed by the hole dimensions, by the smoothness of the bore walls and by the sharpness of the outlet edges. There should be the greatest possible agreement between individual Denier numbers and the diameters of individual threads. This can be achieved only if the same amount of spinning solution flows through the entire number of holes within a given time, and all the holes must therefore have the same flow resistance. This implies identical form and dimensions for the bore holes and identical surface condition of the bore walls.

Spinneret manufacturers can guarantee the bore hole diameter within a tolerance of $\pm 1-2$ micron. The high surface finish of the bore wall coupled with the sharpness of the edges and freedom from burrs and pitting on the outlet side successfully prevent clogging and assure long life between maintenance periods.

\section{Arrangement of Holes}

The arrangement of the holes in the face of the spinneret is dependent on the number of holes
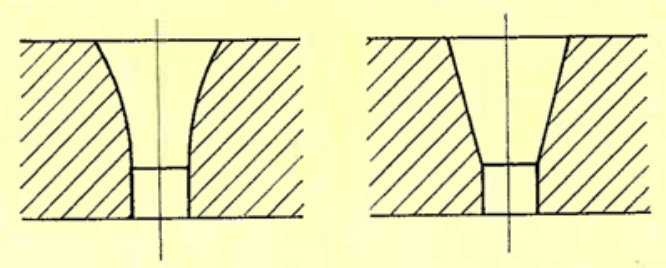

The satisfactory performance of a spinneret depends upon the correct shape and accuracy of the holes. These normally consist of a cylindrical section about 1 to 1.5 times the diameter in length, with a hyperbolic or conical lead-in. Particular care must be taken to ensure both a smooth blending of the lead-in with the straight capillary and the sharpness of the junction with the outlet face 
as well as on the spinning conditions. The arrangements chiefly in use today are illustrated in the accompanying drawing. The concentric pattern as shown at A provides the most uniform use of the area; individual holes are arranged in concentric and equidistant circles. The distance between the holes along each circle is roughly the same as that between the circles. The concentric pattern is used for rayon and for tyre cord spinnerets as well as for staple fibre spinnerets up to about 3,600 holes.

Radial patterns, shown at $B$, with undrilled paths which facilitate contact of the coagulating bath with threads issuing from the central holes, are used more especially for staple fibre spinnerets with high numbers of holes. This daisy pattern divides the drilled area into segments. In another variation, the fan pattern $E$ is used, each of the 10 or 12 segments being subdivided at a distance of half the radius from the centre. Another variation, $\mathrm{D}$, called the ring-road pattern, has undrilled concentric ring-roads in addition to the radial paths. Compared with other types of hole arrangements, this pattern has a service cycle up to 25 per cent longer; that is, a uniform thread diameter is maintained for far longer than for multi-hole staple fibre spinnerets with a concentric hole pattern. The ray pattern, C, is characterised by from 2 to 5 sets of hole circles radiating outwards from the centre.

The distance between individual holes is mainly dependent on the thickness of the spinneret face. Generally speaking the distance should not be less than 80 per cent of the face thickness, as if the distance were smaller there would be a risk that adjacent holes might be deformed during drilling. There is, therefore, a limit to the number of holes per spinneret.

\section{Spinneret Dimensions and Number of Holes}

Spinneret dimensions are generally dependent on the number of holes, which in turn is governed by the number of individual threads required for any particular yarn. For the production of rayon for fabrics small spinnerets are used, such as the one shown in the illustration on page 7, with from 12 to 150 holes. For tyre cord they will range up to $20 \mathrm{~mm}$ in diameter with from 500 to 4,000 holes, while for staple fibre spinnerets will vary in diameter up to some $115 \mathrm{~mm}$ with as many as 15,000 holes, although staple fibre manufacture also requires larger sizes in various shapes with up to 60,000 holes per spinneret.

For given operating conditions and spinneret shape, the thickness of the sheet or spinneret face is chiefly governed by the mechanical strength of the material. It normally ranges from 0.23 to 0.50 $\mathrm{mm}$.

\section{Surface Polish of Outer Spinneret Face}

It has been made clear that the spinning properties of a spinneret as well as the quality of the spun
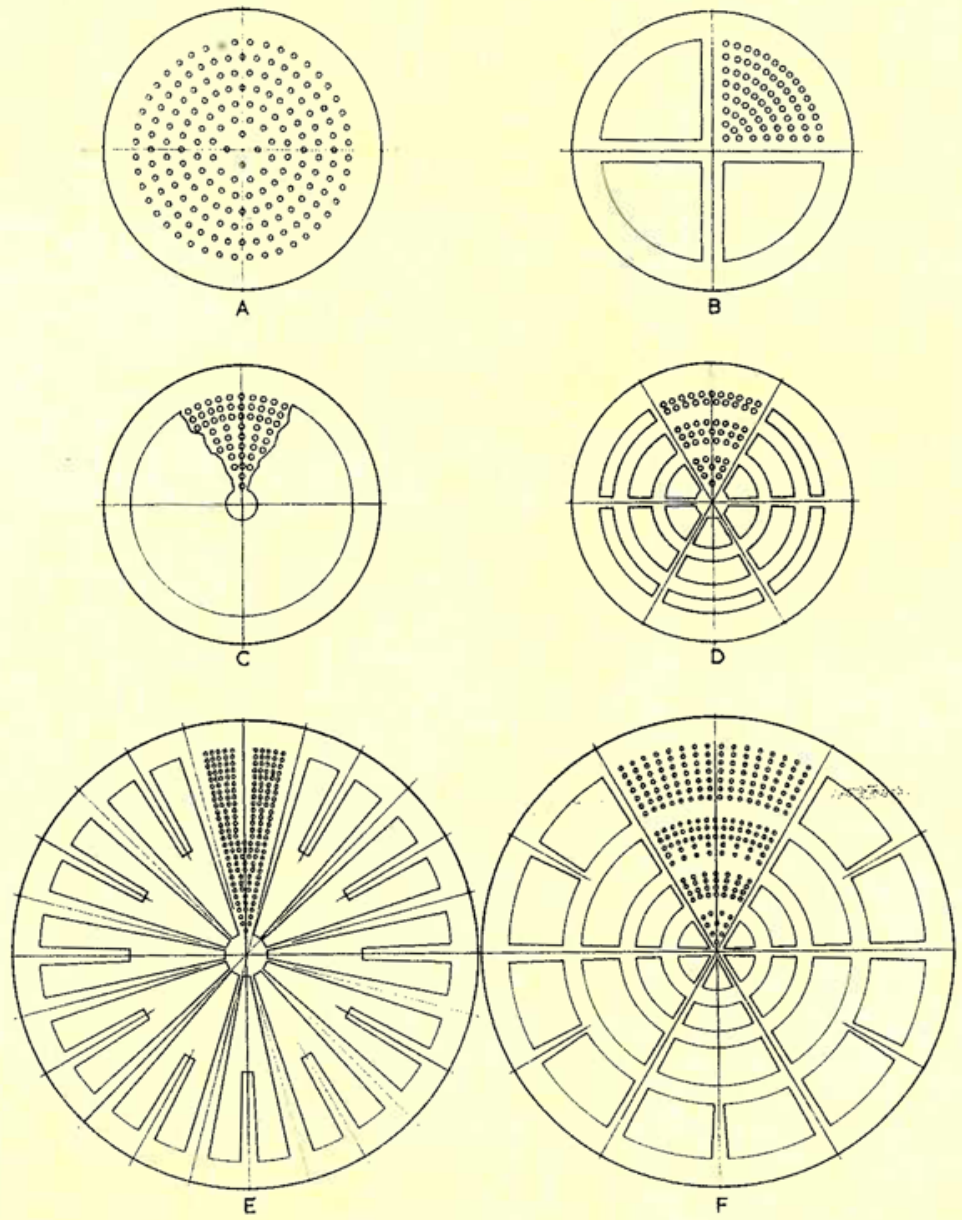

The arrangement of the holes in spinnerets is dependent both on the number of holes and on the spinning conditions. These are some of the principal arrangements used in modern viscose rayon spinning production 
Drilling and polishing the holes in a spinneret are intricate operations demanding considerable skill and accuracy and the use of a binocular microscope built into the equipment. Here a spinneret is being drilled with 40,000 holes in the works of Degussa

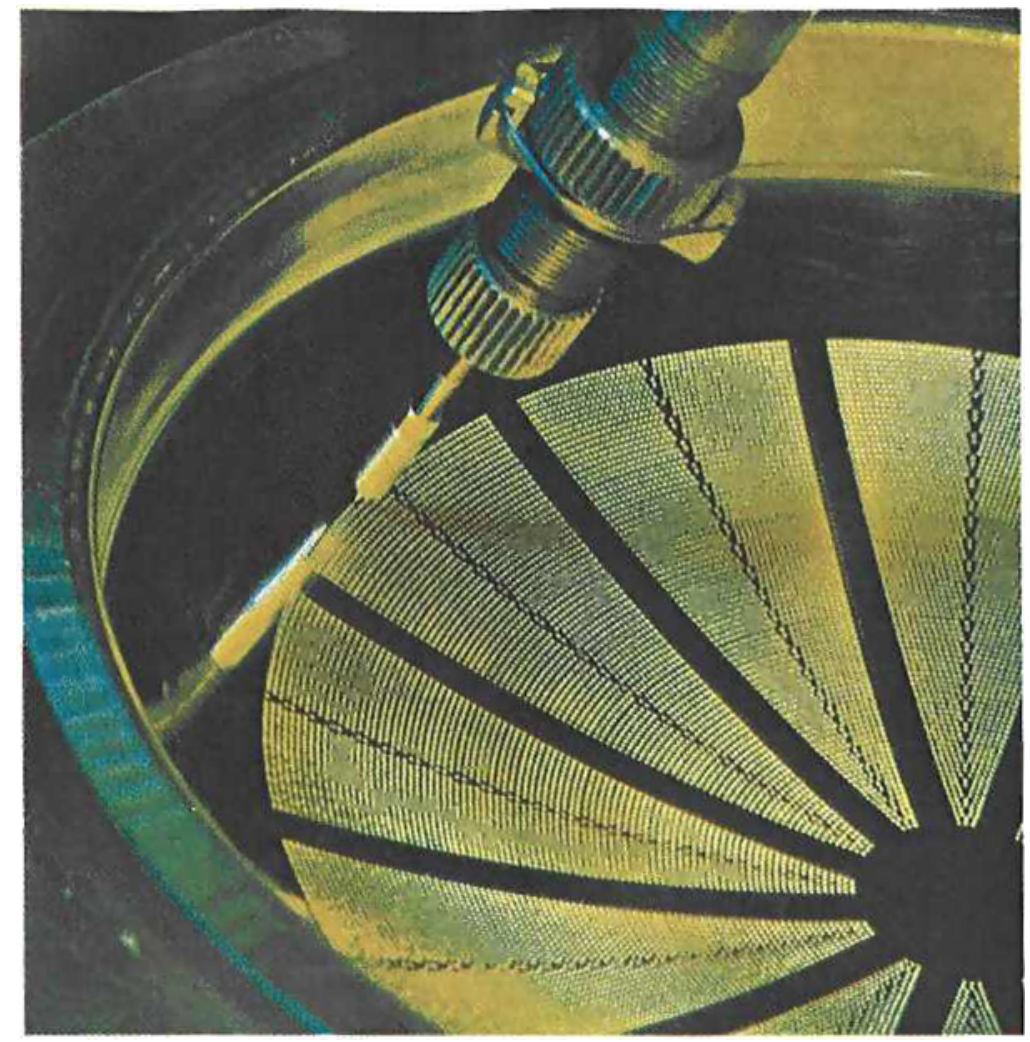

thread are dependent on the sharpness and burr-free surfaces of the holes on the outlet side. Clogging of the holes is directly related to the finish of the outlet edges and the polish of the outer face of the spinneret. The quality of the polish, even at a distance from the holes, is of the greatest importance because crystallised salts tend to accumulate on rough surfaces; once a foreign body has settled on any part of the outer face of the spinneret it becomes a nucleus for further agglomerations of solid particles. These agglomerations slowly spread towards the lips of the holes and tend to clog the outlets. This is the reason why the outer face requires great care in polishing. In order to guard the bore walls and outlet edges from contact with the abrasive used, the holes are usually filled with glass which is subsequently removed by melting.

\section{Future Prospects}

World production of chemical fibre was 9.3 million tons in $1971 ; 3$ million tons or roughly 32 per cent was accounted for by viscose rayon, the remainder was taken up by synthetic fibre. Precious metal alloy spinnerets are used not only to produce viscose rayon but also acrylonitrile fibres. In the foreseeable future such spinnerets, more especially those in platinum-gold alloys will occupy an important place in the production of man-made fibres.

\section{References}

1 C. F. Cross, E. J. Bevan and C. Beadle, British Patent $8700(1891)$

2 C. H. Stearn, British Patent 1020 (1898)

3 M. Müller und P. Koppe, German Patent 187,947 (1905)

4 W. Reents and F. Eilfeld, German Patent 221,572 (1909)

5 E. Grafried, K. Protzmann, K. Ruthardt u. H. Speidel in: Festschrift "Hundert Jahre Heraeus", Hanau 1951 , p. 43

6 R. Pummerer (Ed.), Chemische Textilfasern, Filme und Folien, Stuttgart, 1953, p. 397

7 H. Holzmann in: Degussa Metall-Berichte. Frankfurt 1941, p. 136

8 W. P. Dreaper, British Patent 260,672 (1925)

9 G. Siebert G.m.b.H., German Patent 584,549 (1929)

10 L. Nowack, U.S. Patent 1,946,231 (1930)

$11 \mathrm{~W}$. Goedecke in: Festschrift zum Fünfzigiährigen Bestehen der Platinschmelze G. Siebert G.m.b.H. Hanau 1931, p. 99

12 L. Nowack, Z. Metallkunde, 1930, 22, 94

13 W. C. Heraeus, German Patent 554,502 (1930) Degussa, Swiss Patent 151,732 (1930)

14 W. C. Heraeus, German Patent 535,688 (1928)

15 A. T. Grigorijew, Ann. Inst. Platine, 1928, 6, 184

A. T. Grigorijew, Z. anorg. allgemeine Chem., 1929, 178 97

16 C. H. Johansson and J. O. Linde, Ann. Phys., 1930, 5 762

17 A. S. Darling, R. A. Mintern and J. C. Chaston, $\mathcal{F}$. Inst. Met., 1952--53, 81, 125

18 W. C. Heraeus, German Patent 691,061 (1935)

19 Degussa, German Patent 873,145 (1936)

20 Degussa, German Patent 1,075,838 (1939)

21 Johnson Matthey, British Patent 1,112,766, (1966)

22 H. Schmid, Metall, 1958, 12, 612

23 W. Funk and R. Schumm, Chemiefasern/Textilindustrie, $1972,22,518$ 